\title{
Clinical Outcomes in Neonates Undergoing Lung Resection
}

\author{
Hemonta Kr. Dutta ${ }^{1}$ \\ ${ }^{1}$ Department of Pediatric Surgery, Assam Medical College, \\ Dibrugarh, Assam, India \\ J Child Sci 2017;7:e156.
}

We read the letter from Beuy Joob and Viroj Wiwanitkit in response to our article "Evaluation of Clinical Outcome in Neonates Undergoing Lung Resection for Congenital Lesions" published recently in your journal. ${ }^{1}$ The authors stated that patient preparation and underlying health condition of the patients are two main concerns and should have been discussed in more detail. They also mentioned that thoracoscopy is the ideal surgical technique in such patients. In our study, we evaluated and followed up the children by clinical parameters as well as with imaging studies. Of the 26 patients, 5 children required surgery on emergency basis, and 4 of them had congenital lobar emphysema. The patients with congenital cystic adenomatoid malformation (CCAM) and one patient with bronchogenic cyst presented with secondary infection of the affected lobe and reported to us only after they failed to respond to conservative treatment under care of pediatrician. These patients were admitted under our care, and surgery was offered only after their clinical condition stabilized or improved. Patients in this group, in fact, had most of the postoperative complications that we recorded in our series. Three asymptomatic patients in the series could have been followed up without surgery. But we decided on surgical treatment, as these patients hailed from remote areas and could not have reported in time in the event of any complications. Risk of developing malignancy in future in such benign lesions was also another concern. Objective tests, such as lung function test, were not employed during follow-up in our series. There is a lack of consensus in the literature regarding recovery
Address for correspondence Hemonta Kr. Dutta, MBBS, MS, MCh, Department of Pediatric Surgery, Assam Medical College, APQ-8, L-lane, Dibrugarh, P.O. Borbari, 786002, Assam, India (e-mail: hemontdut@gmail.com).

of lung function following lung resection or ideal age of the patient at the time of surgery as we have discussed in the article. A recent study has shown that surgical treatment appears to be safe at all ages, with no mortalities and similar rates of complications between age groups. ${ }^{2}$ Although thoracoscopy is the ideal surgical procedure in such patients, it is a technically demanding procedure and has a long learning curve. ${ }^{3}$ In a metaanalysis, Downard et al found that there were only few articles in the available English literature providing definitive recommendations for care of the patient with a congenital airway malformations and none reported level I or II evidence. ${ }^{4}$ The author recommended early resection of such lesions.

\section{References}

1 Dutta HK, Bora M, Saikia D. Evaluation of clinical outcomes in neonates undergoing lung resection for congenital lesions: experience in a developing country. J Child Sci 2017;1:e4-e9

2 Sullivan KJ, Li M, Haworth S, et al. Optimal age for elective surgery of asymptomatic congenital pulmonary airway malformation: a meta-analysis. Pediatr Surg Int 2017;33(06):665-675

3 Park S, Kim ER, Hwang Y, et al. Serial improvement of quality metrics in pediatric thoracoscopic lobectomy for congenital lung malformation: an analysis of learning curve. Surg Endosc 2017;31 (10):3932-3938

4 Downard CD, Calkins CM, Williams RF, et al. Treatment of congenital pulmonary airway malformations: a systematic review from the APSA outcomes and evidence based practice committee. Pediatr Surg Int 2017;33(09):939-953 received

October 31, 2017

accepted after revision

November 29, 2017
DOI https://doi.org/

10.1055/s-0037-1618562.

ISSN 2474-5871.
Copyright @ 2017 Georg Thieme Verlag License terms

KG Stuttgart · New York 